\title{
KEARIFAN LOKAL DAN CIRI KEBAHASAAN TEKS NARATIF MASYARAKAT IBAN
}

\author{
Dedy Ari Asfar \\ Balai Bahasa Provinsi Kalimantan Barat \\ email: dedyprim@yahoo.com
}

\begin{abstract}
Abstrak
Penelitian ini bertujuan mendeskripsikan kearifan lokal dan ciri kebahasaan teks naratif masyarakat Iban. Sumber data penelitian adalah tiga cerita Iban dari Lembah Sungai Rimbas, Sarawak, Malaysia, yaitu Kumang Nupi' Sawa', Entimu Nupi' Keli', dan Tekura'. Proses pentranskripsian teks menggunakan pencatatan secara fonetik dengan sistem International Phonetic Alphabet (IPA). Hasil transkripsi dan terjemahan kemudian diolah dengan komputer menggunakan program shoebox untuk menghasilkan database dan interlinear text. Hasil penlitian sebagai berikut. Pertama, kearifan lokal teknologi tangkap ikan tradisional (acar, paca", ginte", mukat, jala, tubay, dan bubu). Kedua, kearifan lokal adat berladang dan bergotong royong (nunuw, kemaraw, tugal, nugal, bantun, mantun, dan gutung-ruyung). Ketiga, kearifan lokal menyabung ayam dan bermain gasing $\left(\mathrm{rabu}^{\gamma} \mathrm{K}\right.$ dan paKkT"). Keempat, teks naratif lokal ini mengandung ciri-ciri bahasa Iban secara fonologi dan morfologi serta ciri-ciri puitiknya.
\end{abstract}

Kata kunci: kearifan lokal, ciri bahasa, teks naratif, etnoputika

\section{LOCAL WISDOM AND LANGUAGE FEATURES OF IBAN PEOPLE'S NARRATIVE TEXTS}

\begin{abstract}
This study aims to describe local wisdom and language features of Iban people's narrative texts. The data sources were three Iban stories from Rimbas Basin, Sarawak, Malaysia, namely Kumang Nupi' Sawa', Entimu Nupi' Keli', and Tekura'. The text transcribing process used the phonetic transcription with the International Phonetic Alphabet (IPA) system. The transcription and translation results were computerized using the shoebox program to generate the data base and interlinear text. The results of the study are as follows. The first is the local wisdom in the traditional fishing technology (acar, paca", ginte", mukat, jala, tubay, and bubu). The second is the local wisdom in the farming tradition andmutual cooperation (nunuw, kemaraw, tugal, nugal, bantun, mantun, and gutungruyung). The third is the local wisdom in the cockfighting and spinning top playing $\left(\mathrm{rabu}^{\gamma} \mathrm{K}\right.$ and paKkT"). The fourth is that the local narrative texts phonologically and morphologically contain the Iban language features and their poetic characteristics.
\end{abstract}

Keywords: local wisdom, language features, narrative texts, ethnopoetics

\section{PENDAHULUAN}

Istilah Iban berasal dari kosakata orang Kayan, yaitu "Ivan" berarti pengembara (Jensen, 1974; King, 1993). Namun, Richards (1981:111) mengemukakan bahwa istilah Iban dalam bahasa Iban bermakna orang. Istilah Iban ini dikenal oleh masyarakat dunia sebagai suku Dayak yang ada di dua negara, yaitu Kalimantan Barat (Indonesia) dan Sarawak 
(Malaysia). Di Sarawak Iban merupakan penduduk mayoritas dibandingkan sukusuku lokal lainnya. Di Kalimantan Barat Iban merupakan satu suku lokal yang hanya ada di Kabupaten Kapuas Hulu dan Bengkayang. Namun, di Kalimantan Barat penamaan bahasa dalam kelompok ini melingkupi beberapa suku lokal, seperti Kantuk, Mualang, Seberuang, Ketungau, Desa, dan Iban.

Berdasarkan tradisi lisan Iban di Sarawak nenek-moyang Iban pada mulanya berasal dari Lembah Sungai Kapuas, Kalimantan Barat, Indonesia. Kemudian, dari Lembah Sungai Kapuas komunitas ini memasuki wilayah Batang Lupar dan seterusnya menyebar ke seluruh wilayah Sarawak, secara bertahap (Sandin, 1977). Gelombang perpindahan mereka pertama kali sekitar pertengahan abad ke-16, yaitu dari Sungai Kapuas melalui aliran Sungai Batang Lupar kemudian mendiami Lembah Sungai Undup. Setelah lima generasi, berikutnya mereka berpindah dari Undup ke daerah utara, timur, barat, dan akhirnya menempati semua sungai utama di Sarawak (Padoch, 1982; Freeman, 1992).

Iban merupakan suku asli Pulau Borneo yang memiliki tradisi lokal bercerita yang dalam terminologi lokal disebut sebagai ensera, pengingat tuai, atau cerita tuai. Teks-teks ini sesungguhnya menarik kalau diteliti aspek bahasa dan etnografinya. Kajian tentang interdisiplin ini disebut dengan etnopuitika yang menggabungkan ilmu bahasa, sastra lisan, dan antropologi dalam satu analisis.

Etnopuitika merupakan kajian penting yang menurut Sherzer \& Woodbury (1987:2) menjadi titik temu empat disiplin ilmu, yaitu linguistik, sastra, antropologi, dan folklor. Dengan demikian, sebagai ancangan teoretis, etnopuitika memiliki kelenturan atau fokus yang berbeda-beda, bergantung pada latar belakang keilmuan peneliti.

Dalam konteks ini, istilah "puitika" mengacu pada teori puitika linguistik
Roman Jakobson, sedangkan istilahpenjelas "etno-" merujuk pada pemikiran linguistik antropologi Edward Sapir. Di samping itu, "etno-" juga menyarankan pentingnya pengetahuan lokal (local knowlwedge), atau perspektif emik, sebagai salah satu alat penjelas atau penafsir atas data kebahasaan yang dipilih, yang lazimnya berupa teks naratif lisan atau teks sastra yang dilisankan/dipentaskan (Kadarisman, 2010).

Sejak tahun 1920 Roman Jakobson telah mengintegrasikan ilmu bahasa dengan sastra. Sebuah makalah yang disampaikannya pada tahun 1960, yaitu "gaya dalam bahasa" (style in language) memaparkan sebuah model dengan tujuan untuk menjelaskan fungsi puitik dalam bahasa (poetic function of language). Bahasa puitik berhubungan dengan masalah yang ada dalam struktur verbal karena linguistik merupakan pengetahuan yang menyeluruh tentang struktur verbal. Bahasa puitik dapat dianggap sebagai bagian yang tak terpisahkan dari displin linguistik (Jakobson, 1996:64-66; Teeuw, 1984:53). Secara berterusan, Jakobson mengembangkan teori bahasa puitik dalam sastra dengan menerapkan deskripsi ilmu lingustik. Konsep bahasa puitik Jakobson ini terus berkembang hingga ke hari ini. Puitika Jakobson ini menjadi inspirasi bagi lahirnya stilistika modern. Malahan, teori ini kini telah dikembangkan dan tidak hanya digunakan untuk menafsirkan teks sastra dari aspek linguistik semata-mata, tetapi juga melihat hubung kait antara sastra dalam masyarakat.

Pemikiran Jakobson ini sesungguhnya telah memberi ilham kepada para pengkaji linguistik, sastra, dan antropologi untuk melihat fenomena sastra lisan dengan berbagai disiplin ilmu. Susulan dari konsep ini satu pendekatan integratif dalam mengkaji sastra telah dikenalkan oleh Jerome Rothenberg pada tahun 1968, yang disebut sebagai etnopuitika melalui jurnal Alcheringa (Tedlock, 1992:81-85). 
Etnopuitika juga didefinisikan sebagai satu pendekatan dalam penelitian folklor atau sastra lisan dengan berusaha menjelaskan sekelompok istilah, konsep, dan frasa linguistik yang terbentuk dalam teks sastra lisan (Amos, 1992:101-118). Dalam definisi yang lebih lanjut, etnopuitika merupakan kajian integratif yang berusaha menjelaskan tidak hanya bentukbentuk linguistik dalam teks sastra tetapi juga konteks sosial, ideologi, pikiran masyarakat, dan seni yang hadir dalam kehidupan sehari-hari masyarakat yang dipresentasikan melalui teks sastra (lihat Bauman, 1978; Sherzer, 1983; Hymes, 1981:337-339). Selain itu, pendekatan etnopuitika juga memberi perhatian pada usaha dalam mencari bentuk-bentuk estetik sastra lisan dan usaha penerjemahan yang akan memberikan sumbangan pada nilai seni agar tidak hilang dalam pertunjukannya (Bauman, 1992:29-40).

Dalam beberapa tahun terakhir ini etnopuitika telah muncul sebagai pendekatan yang berusaha mengeksplorasi penggunaan bahasa perumpamaan dan simbol budaya lisan sebagai cara untuk menafsirkan emosi dan ide yang disampaikan oleh seorang penutur kepada masyarakat atau audien budaya lisan. Diantara peneliti yang telah mencurahkan perhatian terhadap teks-teks lisan dengan menerapkan kaidah etnopuitika adalah Hymes (1981) yang menekankan pentingnya the universality of the lines 'keuniversalitasan pembaitan" dalam mentranskripsi dan menerjemahkan teks cerita Indian Amerika. Hymes berhasil mentranskripsi genre sastra lisan masyarakat Chippewa, Haida, dan Kwakiutl dengan sangat hatihati. Kehati-hatiannya inilah membuat Hymes berhasil menerjemahkan teks masyarakat asli benua Amerika tersebut dalam bahasa Inggris menjadi sebuah puisi naratif. Bahkan, kaidah etnopuitika pun digunakan seorang antropolog bernama Dennis Tedlock (1992:81-85) saat mentranskripsi teks lisan dengan menekankan pada the art of sounding the text, atau "seni melantunkan teks" yang berfungsi untuk memperdengarkan kepada pembaca bagaimana sebuah narasi atau epik dilantunkan oleh penuturnya. Tedlock mengusulkan penggunaan sistem transkripsi dengan huruf besar untuk suara keras, garis panjang di belakang kata untuk bunyi vokal yang sangat panjang, tanda-titik pemisah larik untuk berhenti dua detik, dan beberapa tanda baca lainnya.

Penelitian lain di Alam Melayu dilakukan Sweeney (1976:15-88) seorang pakar sastra lisan Melayu yang melihat gaya dan persembahan dalam cerita. Misal dalam cerita Pak Pandir terjadi penghilangan konsonan, contohnya hilangnya konsonan $k$ dan s pada kalimat "Alau ada Andihenang (Kalau ada Andih senang). Penyebutan $s$ sebagai $c$, misalnya "Ucah ak akan aci" (Susah nak makan nasi). Pemuculan frasa berirama misalnya "Bar ketibar bentang tikar lebar-lebar". Ada juga yang menutup cerita dengan nada yang semi-nonsense "Pak Endir Kutuk, Pak Endir Laknat; Pak Endir kentut, terbit punat" yang umumnya muncul dalam pertuturan di Kelantan. Di Perak biasa juga muncul penutup cerita dengan ekspresi "Pak Pandir telungkup, Pak Pandir telingkap". Selain itu, ada juga penelitian di Indonesia yang dilakukan Kadarisman (1999) tentang konteks dan gaya pertuturan penutur naratif perkawinan dalam bahasa Jawa di Malang dan Solo. Penelitian ini mengkaji bentuk-bentuk fonetik, fonologi, morfologi, sintaksis, dan alih kode serta konteks bahasa-sastra dalam domain budaya Jawa. Secara fonologis kajian ini mendapati sesekali adanya penekanan kata dan frasa yang disertai pemanjangan vokal. Bahkan, ada penggantian glotal hambat ["] dengan glotal frikatif [h] pada bunyi vokal di awal kata, seperti pada kata amangku 'memangku', diucapkan hamangku.

Berbagai temuan itu menunjukkan bahwa pendekatan tersebut dapat di- 
terapkan pada teks naratif lisan untuk mendeskripsikan struktur bahasa secara struktural, seperti fonologi, morfologi, sintaksis, dan semantik. Namun, tulisan ringkas ini hanya menekankan bahasa dalam kearifan lokal teks naratif Iban dengan berdasarkan transkripsi dan terjemahan teks-teks lisan mengikuti prinsip ilmu linguistik. Transkripsi dan terjemahan dilakukan dengan memposisikan teks naratif menjadi baris-baris berdasarkan jeda akhir sebuah kalimat pertuturan dari sang pencerita. Penelitian ini mentranskripsi teks dengan menerapkan simbol huruf fonetik dan menerjemahkannya. Penulis berusaha mengadopsi etnopuitika sebagai satu pendekatan dalam penelitian naratif lisan dengan berusaha mendeskripsikan tata bunyi kata, menjelaskan istilah, konsep, dan frasa linguistik yang terbentuk dalam teks naratif lisan yang mengandung kearifan lokal dalam kalimat yang dikutip.

Ringkasnya, tulisan ini bertujuan untuk mengetahui ciri-ciri bahasa Iban di dalam teks naratif yang memiliki kearifan lokal. Tulisan ini menganalisis tiga cerita Iban dari Lembah Sungai Rimbas, Sarawak, Malaysia, yaitu Kumang Nupi' Sawa', Entimu Nupi' Keli', dan Tekura'. Hasil penelitian ini diharapkan berguna dalam (1) bidang linguistik, khususnya dialektologi bahwa sastra lisan dapat menjadi korpus utama dalam penelitian dialek; (2) pengajaran sastra, khususnya dalam mengajarkan nilai-nilai kearifan lokal yang dapat diambil sebagai pelajaran tentang khazanah kekayaan budaya etnik; (3) penyusunan kamus bahasa Iban, baik dalam penyusunan entri maupun dalam pendefinisiannya.

\section{METODE}

Penelitian ini menggunakan kaidah kualitatif. Penulis turun langsung ke lapangan dan menetap di lokasi kajian dengan menerapkan metode observasi-partisipasi (Baharuddin, 1992:11). Observasi partisi- pasi merupakan model penelitian lapangan dengan ciri keterlibatan peneliti dengan realitas dunia itu sendiri (Atkinson dan Martyn Hammersley, 2009:317)

Ada dua teknik yang digunakan dalam pengumpulan data, yakni wawancara dan perekaman (Hutomo, 1991:82). Teknik perekaman didukung teknik wawancara yang disertai dengan pencatatan lapangan (field notes), baik sebelum maupun sesudah perekaman naratif lisan dilakukan. Bahkan, catatan lapangan dilakukan, baik oleh peneliti maupun partisipan .

Alat-alat yang digunakan untuk merekam teks lisan Iban adalah tape recorder TCM Sony dan beberapa kaset rekaman Sony 60 menit. Informan dipilih berdasarkan kepandaian dalam bercerita, baik perempuan maupun lelaki; tua maupun muda. Secara sengaja peneliti menciptakan suasana tradisional dalam perekaman sastra lisan ini dan menciptakan suasana informal (amatir) (Sweeney, 1974:48-55).

Perekaman data lapangan dilakukan pada tanggal 24-30 Desember 2002 di Rumah Panjang Iban Ulu Rimbas dan Nanga Ulai, Sarawak, Malaysia. Pada bulan Januari-Maret 2003 hasil rekaman ditranskripsi dan diterjemahkan oleh asisten peneliti yang sudah dibekali ilmu fonetik yang berasal dari Rumah Panjang Nanga Ulai. Transkripsi dan terjemahan awal ini hanya untuk memudahkan kerja peneliti saat mentranskripsi dan menerjemahkan kembali teks naratif tersebut. Selanjutnya, pada tanggal 6-12 Mei 2003 penulis melakukan kunjungan untuk kali kedua. Kajian lapangan yang kedua ini untuk merekam teks lisan Iban di kampung yang belum dikunjungi. Selain itu, peneliti mentranskripsi dan menerjemahkan kembali sekaligus memeriksa dan memvalidasi hasil transkripsi yang sudah dilakukan pada bulan JanuariMaret. Penulis mentranskripsikan dan menerjemahkan kembali teks dengan asisten peneliti lapangan lain dari Rumah Panjang Babu Tengah untuk memastikan 
pencatatan secara fonetisnya agar teks lisan dapat dijadikan korpus yang siap dianalisis secara linguistik, sastra, dan antropologi.

Proses pentranskripsian teks-teks naratif lisan yang diperoleh menggunakan pencatatan secara fonetik dengan menggunakan sistem International Phonetic Alphabet (IPA). Penerjemahan dengan dua jenis teknik, yaitu teknik terjemahan kata demi kata untuk menunjukkan makna leksikal kata-kata yang bersangkutan, dan terjemahan bebas untuk menunjukkan dan mengetahui makna kata dalam hubungannya dengan kalimat atau untuk menerangkan makna berdasarkan konteks sosial cerita dan makna kias yang ada dalam teks. Hasil transkripsi dan terjemahan ini kemudian diolah dengan komputer menggunakan program shoebox. Program ini berguna bagi peneliti untuk membuat database'pangkalan data' bahasa Iban yang berfungsi sebagai penerjemah terhadap teks cerita yang di-interlinear-kan. Hasil komputerisasi ini menghasilkan korpus teks yang sistematis, rapi, dan mudah untuk dianalisis serta menghasilkan glosari atau kamus mini bahasa Iban. Selanjutnya, demi kepentingan analisis dalam tulisan ini korpus teks naratif Iban yang ada kemudian dibedah dengan memilih kata-kata yang mengandung nilai-nilai kearifan lokal Iban yang masih diamalkan. Kosakata Iban berbentuk frasa, kalimat, dan paragraf yang mengandung nilai-nilai kearifan lokal yang dikutip ini kemudian dianalisis secara linguistik dengan mendeskripsikan ciri-ciri bahasa Iban yang menjadi ciri khas teks naratif lisan ini.

\section{HASIL DAN PEMBAHASAN \\ Bahasa dalam Teks Kearifan Lokal}

Peursen (2001:37) mengemukakan mitos tidak hanya berfungsi sebagai hiburan tetapi juga berfungsi sebagai laporan mengenai peristiwa-peristiwa yang dulu pernah terjadi. Bahkan, mitos dapat menjadi pedoman untuk mempelajari kebi- jaksanaan manusia. Artinya, kita dapat mengambil hikmah, nilai, dan kearifan lokal dari cerita yang disampaikan.

Sastra lisan bagi masyarakat pemilik teks merupakan wujud dari kearifan lokal Iban sebagai sebuah sistem pewarisan pengetahuan lokal (local knowledge) (Geertz, 1983:167) dan berfungsi sebagai sebagai sistem proyeksi, untuk pengesahan kebudayaan, dan sebagai alat pemaksa berlakunya norma sosial dan sebagai alat pengendali sosial (Hutomo, 1991:69-76). Fungsi-fungsi sastra lisan ini sejajar dengan konsep kearifan lokal yang dikemukakan Putra (2008:12), yaitu kearifan lokal merupakan "perangkat pengetahuan dan praktik-praktik, baik yang berasal dari generasi-generasi sebelumnya maupun dari pengalaman berhubungan dengan lingkungan dan masyarakat lainnya milik suatu komunitas di suatu tempat, yang digunakan untuk menyelesaikan secara baik dan benar berbagai persoalan dan/ atau kesulitan yang dihadapi." Nilai-nilai kearifan lokal ini menurut Effendy (2007) muncul dalam sastra lisan dengan simbolsimbol tertentu dalam menyampaikan pesan kepada masyarakat pemilik budaya atau sastra lisan tersebut.

\section{Kearifan Lokal Teknologi Tangkap Ikan Tradisional}

Dalam teks naratif Kumang Nupi' Sawa' versi Ci' dan Inau digambarkan kearifan lokal Iban dalam menangkap ikan. Teks naratif ini mendeskripsikan pengetahuan lokal Iban dalam menangkap ikan melalui pemakaian istilah [mansay]. Kata mansay dalam bahasa Iban berarti menangkap ikan dengan sejenis alat berbentuk keranjang besar yang memanjang terbuat dari rotan. Kata mansay merupakan bentuk turunan dari bentuk dasar pansay. Dari bentuk kata pansay dan mansay ini ada bentuk turunannya lagi yang merujuk pada makna alat untuk menangkap ikan, yaitu dalam bahasa Iban disebut pemansay. Teknik tangkap ikan dengan mengguna- 
kan pemansay dilakukan ketika ingin menangkap ikan di pinggir-pinggir sungai. Teknologi tangkap ikan tradisional ini terdapat dalam dua teks berikut.

\section{Teks Naratif Kumang Nupi' Sawa' versi Ci' kumaK mansay \\ Kumang N+tangkap-ikan \\ ta" mansay. \\ tiba-tiba N+tangkap-ikan \\ Kumang pergi menangkap ikan.

mansay $\mathrm{nmu}^{\mathrm{w}}$ sawT",
$\mathrm{N}$ +tangkap-ikan $\mathrm{N}$ +temu Sawa
anak sawT".
anak Sawa

Kemudian mendapatkan tangkapan seekor anak ular Sawa.

Teks Naratif Kumang Nupi' Sawa' versi Inau nserT kumaK nupi" sawT".

cerita Kumang N+pelihara Sawa

Cerita Kumang memelihara anak Sawa.

radi $^{y}$ kumaK $\operatorname{tadi}^{\mathrm{y}}{ }^{\prime \prime}$ muri

$\mathrm{N}+$ jadi Kumang tadi $\mathrm{N}+$ bunyi

$\mathrm{ku}^{\prime \prime}$ pun

seperti mulai

Kgi" iyT ro" tadi ${ }^{\text {"' }}$ mansay.

punya dia itu tadi $\mathrm{N}$ +tangkap-ikan

Jadi menurut ceritanya, Kumang ini tadi menangkap ikan.

mansay tadi ${ }^{y \prime}$ buliah sawT"

N+tangkap-ikan tadi dapat Sawa

anak tadi ${ }^{\prime \prime \prime}$.

anak tadi

Menangkap ikan, lalu tertangkap anak ular Sawa.

Teks naratif Iban ini mengambarkan pengetahuan lokal tentang teknik menangkap ikan pada masyarakat setempat. Berdasarkan teks ini pengetahuan lokal Iban mengenai teknik menangkap ikan dapat diinventarisasi lebih lanjut dengan bertanya kepada informan. Wawancara mendalam menghasilkan bahwa ada beberapa cara menangkap ikan dalam masyarakat Iban, sepeti acar, paca", ginte", mukat, jala, tubay, dan bubu. Acar merupakan sejenis kail banyak mata yang ditarik di dalam air tanpa menggunakan umpan. $P a c a "$ merupakan alat pancing dengan mata kail berukuran besar yang digunakan untuk menangkap ikan besar. Ginte" merupakan pancing dengan mata kail berukuran kecil. Mukat adalah menangkap ikan dengan pukat atau jaring besar dan panjang yang dibentangkan di sungai. Jala merupakan satu teknik menangkap ikan dengan menggunakan jaring bulat dengan menebarkannya ke air sambil memanfaatkan tangan kiri dan kanan sebagai pembuka jaring. Tubay merupakan cara menangkap ikan dengan menggunakan racun dari akar pohon tuba. Teknik ini dapat membuat ikan seperti mabuk dan tidak sadarkan diri sehingga mengambang di permukaan air. Kata tubay 'tuba' mengalami proses morfofonemik sehingga membentuk kata turunan menjadi nubay 'menuba'. Bubu merupakan alat untuk menangkap ikan yang dibuat dari bambu yang dianyam dan dipasang dalam air. Teknik ini untuk menggiring ikan agar masuk ke dalam perangkap (bubu) yang di dalamnya diberi umpan sehingga membuat ikan tidak dapat keluar lagi.

\section{Kearifan Lokal Adat Berladang dan Ber- gotong Royong}

Ada tiga teks naratif dari tiga orang penutur Iban yang menggambarkan adanya kearifan lokal adat berladang dan bergotong-royong yang sampai sekarang masih diamalkan oleh masyarakatnya. Pertama adalah teks naratif Kumang Nupi' Sawa' yang dituturkan $\mathrm{Ci}^{\prime}$; kedua, teks naratif Kumang Nupi' Sawa' yang dituturkan Inau; dan ketiga, teks naratif Entimu' Nupi' Keli' yang dituturkan Ito.

Teks-teks naratif lisan Iban ini mengemban kearifan lokal sebagai pengesahan adat tradisi menanam mengikuti musim 
dalam aktivitas pertanian Iban. Berdasarkan teks Kumang Nupi' Sawa' penjelasan tentang proses dan teknologi pertanian Iban tampak dalam konflik klimaks antara Kumang dan ular Sawa. Peristiwa dalam cerita tersebut menyebut proses menanam masyarakat Iban, yaitu dengan membakar ladang yang hendak dijadikan tempat bercocok tanam pada musim kering, kemudian menugal (memasukkan benih padi ke dalam lubang tanah). Setelah padi tumbuh dan mulai berkembang, tahap selanjutnya adalah menjaga padi tersebut dengan membersihkan/mencabut rumput-rumput di sekitar padi yang dalam istilah bahasa Iban disebut bantun, mantun, seperti dalam teks naratif Entimu' Nupi' Keli'. Perhatikan kutipan di dalam teks-teks berikut.

\section{Teks Naratif Kumang Nupi' Sawa' oleh $\mathrm{Ci}^{\prime}$ \\ udah uraK nunu ${ }^{w}$ diyT"}

udah orang $\mathrm{N}+$ bakar huma di sana, sesudah orang membakar huma di sana,

uraK mayuah bYlabuah gawT" diyT" orang ramai mulai bekerja di sana

raK gutuK-ruyuK diyT".

orang bergotong-royong di sana

orang ramai mulai bekerja di sana untuk bergotong-royong.

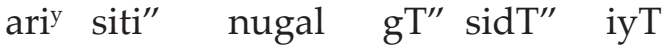

hari satunya $\mathrm{N}+$ tugal juga mereka dia

Hari berikutnya, mereka menanam padi.

Teks Naratif Kumang Nupi' Sawa' oleh Inau kirT ka" mayT uraK Kiray

kira mau waktu orang mengeringkan

Kapan masa orang mengeringkan

rYban ka" kami iban

kayu-rumput mau kami Iban

raw ka" nunu ${ }^{\mathrm{w}}$

lalu mau N+bakar kayu-rumput dalam istilah Iban membakar untuk berhuma.

$\mathrm{lu}^{\mathrm{w}}$ Kabas umay balT lalu N+periksa huma kelompok sidT" iyT mereka dia

mYdT" ari kYmaraw

$\mathrm{N}+$ lihat hari kemarau

Lalu memeriksa ke humalah semua orang untuk memastikan sudah musim panas.

Di dalam petikan teks naratif di atas terdapat pilihan kata $\left[\mathrm{nunu}^{\mathrm{w}}\right]$ dan [kemaraw]. Hubungan dua kata itu dalam masyarakat Iban adalah kata [nunuw] 'bakar' dan [kemaraw] 'musim panas' identik dengan tradisi berladang. Artinya, tradisi membakar pada lahan yang akan dijadikan ladang dilakukan pada saat musim panas. Istilah [nunu ${ }^{\mathrm{w}}$ ] berarti membakar yang dalam masyarakat Iban merupakan satu tahapan berladang sebelum tahapan menugal atau membuat lubang di tanah yang akan ditanami benih padi.

Petikan teks di atas juga memberi penjelasan tentang orang Iban yang selalu bergotong-royong mengerjakan huma atau ladang yang ditegaskan dengan pilihan kata dalam teks naratif Kumang Nupi' Sawa' oleh Ci' dengan istilah [gaw $\mathrm{T}^{\prime \prime}$ ] dan [gutung-ruyung], seperti kalimat penutur yang berbunyi uraK mayu ${ }^{a} h$ bYlabu ${ }^{a} h$ gawT" diyT" raK gutuK-ruyuK diyT". Selain itu, konstruksi kalimat pencerita Iban ini sesungguhnya memunculkan bunyi asonansi dan aliterasi dalam teks. Hal ini terlihat adanya kesejajaran irama pada pilihan kata [mayu ${ }^{a} h$ b $\ll l a b u^{a} h$ ] dalam cerita Kumang Nupi' Sawa' yang diceritakan oleh $\mathrm{Ci}^{\prime}$ tersebut. Dengan demikian, konstruksi kalimat ini terdiri atas frasa yang memiliki bunyi asonansi yang berfungsi untuk keindahan bunyi dan memberi penekanan pada kalimat akan aktivitas kerja bersama-sama atau gotong-royong. 
Secara tersurat teks di atas sekaligus mengandung kearifan lokal sebagai pengesahan kebudayaan dan alat pengawas agar norma-norma masyarakat selalu dipatuhi oleh anggota masyarakat dalam kehidupan dan perilaku sehari-hari mereka, yaitu norma untuk saling membantu dan bekerja sama mengamalkan nilai tradisi bergotong-royong. Hal ini sejalan dengan penelitian yang pernah dilakukan oleh Dove (1985:67-122) pada masyarakat Dayak Kantuk sebagai salah satu kelompok Ibanik di Kalimantan Barat bahwa kegiatan, seperti menebas, menebang, menanam, menyiangi, menuai, dan mengangkut hasil ladang melibatkan kerja sama anggota masyarakat lainnya.

Kearifan lokal adat berladang (tradisi menanam padi) juga digambarkan di dalam teks naratif Entimu' Nupi' Keli' yang diceritakan oleh Ito. Teks naratif ini menambah data tentang teknologi pertanian Iban tersebut. Teks ini menggambarkan satu tahapan lagi dalam teknologi menanam padi tradisional lban dengan istilah [bantun] dan [mantun]. Mantun merupakan satu tahapan berladang yang dilakukan untuk membersihkan/mencabut rumput-rumput liar yang tumbuh di sekitar tanaman padi. Perhatikan kutipan teks naratif lisan berikut.

\section{Teks Naratif Entimu' Nupi' Keli' oleh Ito} rumput jabaw padi ${ }^{\mathrm{y}}$ galaw, $\mathrm{kYnu}{ }^{\mathrm{w}}$ " rumput tebas padi jangan begitu ko" iyT

kata dia

$\mathrm{Kanu}^{\text {w" }} \mathrm{kYli}^{\mathrm{y}}{ }^{\prime \prime}$

$\mathrm{N}+$ pada Keli

"Rumput tebas padi jangan," katanya kepada Keli.

bantun $\quad \mathrm{kYli}^{\mathrm{y}}{ }^{\prime \prime} \mathrm{rT}^{\prime \prime}$

cabut-rumput Keli itu

iyT jampat badu ${ }^{\mathrm{w}}$ "

dia cepat berhenti

Keli itu bersihkan rumput. Dia cepat selesai mantun $\quad \mathrm{KYli}^{\mathrm{y} \prime} \mathrm{ti}^{\mathrm{y}}{ }^{\prime \prime}$ nuluK $\mathrm{N}$ +cabut-rumput Keli yang N+tolong. Keli pun menolong mencabut rumput.

Bantun $\quad \mathrm{kYli}^{\mathrm{y} \prime} \mathrm{kYli}^{\mathrm{y} \text { "', }} \mathrm{ku}^{\prime \prime}$ iyT cabut-rumput Keli Keli kata dia "Bersihkan rumput Keli, Keli," katanya.

padi ${ }^{y}$ jabaw rumput galaw padi tebas rumput jangan

"Padi tebas rumput jangan."

Teks naratif Entimu' Nupi' Keli' di atas sangat jelas menggambarkan satu proses dalam sistem perladangan orang Iban. Proses itu tergambarkan dengan istilah [bantun] 'cabut rumput' dan [mantun] 'mencabut rumput'. Istilah-istilah ini hanya digunakan untuk merujuk makna dalam sistem perladangan orang Iban. Kata /bantun/ merupakan bentuk kata dasarnya sedangkan kata/mantun/merupakan hasil proses morfofonemik dari kata /bantun/ yang merujuk pada proses mencabut atau membersihkan rumput di ladang.

Selain itu, permainan bunyi kata oleh pencerita Iban ini juga memperlihatkan kesan yang menarik dan estetik dalam konstruksi kalimat tertentu. Misal, pada kalimat [rumput jabaw padi galaw] 'rumput tebas padi jangan' dalam cerita Entimu' Nupi' Keli' oleh Ito berhasil membentuk formulaik karena kalimat ini dibentuk secara bersubstitusi atau dengan memutar kedudukan kata [rumput] dan [padi] menjadi [padi jabaw rumput galaw] 'padi tebas rumput jangan'. Konstruksi kata ini menghasilkan bunyi puitik dalam teks naratif, yang berfungsi agar pendengar dapat merasakan nilai 'kelucuan dan kebodohan' dari perilaku watak cerita tersebut.

\section{Kearifan Lokal Menyabung Ayam dan Bermain Gasing}

Terdapat juga kearifan lokal yang membenarkan dan mengesahkan adat me- 
nyabung ayam dan bermain gasing dalam masyarakat Iban. Menyabung ayam dan bermain gasing merupakan aktivitas tradisional Iban yang masih diamalkan. Dalam Festival Gawai Burong pada masyarakat Iban adat menyabung ayam menjadi salah satu aktivitasnya ${ }^{4}$

Teks naratif Kumang Nupi' Sawa' memiliki kearifan lokal yang mengandung pesan untuk mengamalkan adat menyabung ayam dan bermain gasing. Hal ini bukanlah sekadar tradisi, ada simbolisme yang diyakini orang Iban terhadap ayam jago. Simbol ayam jago yang kuat dan menang dalam bersabung melambangkan manusia Iban yang kuat dan berhasil dalam pekerjaannya, terutama keberhasilan dalam berladang. Hal ini seperti keyakinan orang Bali terhadap ayam jago dan hubungannya dengan manusia yang jago pula (Geertz, 1992). Petikan teks naratif yang memperlihatkan kearifan menyabung ayam dan bermain gasing adalah sebagai berikut.

Teks Naratif Kumang Nupi' Sawa' versi Inau

$n \mathrm{Ymu}^{\mathrm{w}}$ uraK rabu $^{\mathrm{Y}} \mathrm{K}$ aKkat deh anak

$\mathrm{N}+$ temu orang $\mathrm{N}+$ sabung bangun Part anak

kumaK ka alam lubaK kayu"

Kumang ke dalam lubang kayu

Terdengar ada orang menyabung ayam dia pun keluar dari dalam lubang kayu

$\mathrm{ka}^{\prime \prime} \mathrm{rabu}^{\gamma} \mathrm{K} \mathrm{ka}^{\prime \prime} \mathrm{rabu}^{\gamma} \mathrm{K}$ Kgaw mau N+sabung mau N+sabung dengan

sidT" $\quad \mathrm{KYli}^{\mathrm{Y}} \mathrm{K}$

mereka Keling

untuk ikut serta menyabung dengan Keling dan kawan-kawannya.

iyT paKkT" KYlaban uraK dia pangkah N+lawan orang. Dia bermain gasing melawan orangorang. abis naday tan meh uraK habis tiada kalah Part orang

paKkT" Kgaw iyT

pangkah dengan dia

Tidak ada orang yang mampu mengalahkannya bermain gasing.

Teks di atas bercerita tentang tokoh Kumang yang berhasil selamat dari kejaran Ular Sawa yang akan memakannya. Ular Sawa mati karena tempat persembunyiannya merupakan lahan yang akan dijadikan tempat berladang. Oleh karena itu, tempat tersebut dibakar oleh orang Iban karena akan dijadikan tempat berladang sehingga mengakibatkan Ular Sawa yang berada di tempat itu terbunuh. Kumang yang bersembunyi di dalam batang kayu kemudian hamil dan melahirkan seorang anak hanya gara-gara air kencing seorang lelaki bernama Keling. Anak tersebut bertambah besar dan keluar dari tempat persembunyiannya di batang kayu. Ia keluar untuk menantang orang-orang kampung menyabung ayam dan bermain gasing. Anak tersebut tidak pernah terkalahkan dalam permainan menyabung ayam dan bermain gasing.

Teks di atas sesungguhnya menggambarkan makna simbolik bahwa aktivitas menyabung ayam dan bermain gasing juga berkaitan sebagai penanda permulaan kerja berladang. Aktivitas menyabung ayam ini dilakukan pada waktu antara aktivitas setelah menebas, menebang, dan membakar kawasan yang akan dijadikan tempat berladang. Hal ini tergambar dengan jelas di dalam teks naratif yang menunjukkan adanya aktivitas menyabung ayam dan bermain gasing yang dilakukan setelah orang-orang membakar lahan yang akan dijadikan tempat berladang. Aktivitas menyabung ayam dan bermain gasing dilakukan sebagai sebuah simbolisme doa yang bertujuan agar kegiatan berladang akan berhasil dan tanpa hambatan. Menurut Taslim 
dan Osup (2013) menyabung ayam merupakan satu tahapan sebelum orang Iban menanam padi. Bahkan, ada ritual khusus yang dilakukan pada malam hari sebelum acara menyabung ayam dilakukan pada keesokan harinya, yaitu mengundang lemambang (dukun Iban) untuk melantunkan mantra yang lazim disebut renong sabung.

Dalam istilah lokal Iban menyabung ayam disebut [ $\left.\mathrm{rabu}^{\mathrm{Y}} \mathrm{K}\right]$ dan bermain gasing dengan istilah [pangkT"]. Kata [rabu $\left.{ }^{\mathrm{Y}} \mathrm{K}\right]$ 'menyabung ayam' merupakan bentuk turunan atau hasil proses morfofonemik dari kata [sabu ${ }^{\mathrm{Y}} \mathrm{K}$ ] 'sabung ayam'. Kata [pangkT"] merujuk pada permainan gasing. Kata [paKkT"] menurunkan kata [maKkT"] sebagai sebuah proses morfofonemik yang bermakna aktivitas memainkan gasing dengan cara membanting gasing dengan menghantam pada gasing yang lain. Kata pangkT" dan maKkT" merujuk adat permainan tradisional Iban untuk mengadu ketangkasan dalam memainkan gasing.

Berdasarkan petikan teks-teks naratif lisan yang mengandung kearifan lokal Iban tersebut dapat dilihat bahwa bahasa Iban di Hulu Sungai Rimbas, Sarawak, Malaysia memiliki ciri-ciri yang khas. Secara fonologi teks naratif lisan Iban ini memiliki ciri-ciri bahasa yang memperlihatkan proses diftongisasi vokal tinggi, fenomena yang sama juga terjadi dalam bahasa Melayu di Ulu Terengganu (Collins, 1983). Dalam teks naratif lisan Iban fenomena diftongisasi vokal tinggi berlaku pada akhir kata terbuka. Diftongisasi seperti ini menunjukkan diftong dengan vokal geluncuran, yaitu vokal tersebut bercirikan [+tinggi], misal, [nYmu $\left.{ }^{\mathrm{w}}\right]$ 'menemukan', [nunu $\left.{ }^{\mathrm{w}}\right]$ 'membakar', [ari $\left.{ }^{\mathrm{y}}\right]$ 'hari', [kami' ${ }^{\mathrm{y}}$ ' 'kami'.

Di samping itu, vokal tinggi /u/ dan /i/ mengalami diftongisasi pada posisi suku akhir yang ditutup dengan konsonan $/ \mathrm{A} /$, $/ \mathrm{h} /$, dan $/ \mathrm{N} /$. Corak diftongisasi ini didapati berbeda, yaitu pada posisi /u/ dan /i/ menunjukkan geluncuran [a] di depan // dan /h/ dan geluncuran [Y] di depan //. Contoh data tersebut adalah [kYbua?] 'sejenis tempayan', [pucua?] 'pucuk', [asuah] 'suruh', [uliah] 'dapat', 'mampu', [rabu'N] 'menyabung ayam', dan [kYli'N] 'keling'.

Berdasarkan teks naratif lisan yang dikaji, terdapat tujuh bunyi vokal, yaitu [i], [e], [u], [o], [Y], [a] dan [T]. Namun, secara fonemik hanya terdapat enam vokal, yaitu dua jenis vokal depan, /i/ dan /e/; dua vokal belakang, yaitu /u/ dan /o/; dan, dua vokal tengah, yaitu /Y/ dan /a/. Hal ini selaras dengan yang ditemukan Adelaar (1995). Vokal tengah/a/ memiliki alofon /T/, yang wujud pada posisi akhir kata dalam suku kata terbuka dan suku yang berakhir dengan /A/. Hal ini telah dibuktikan melalui kajian Chong Shin (2003) ketika menganalisis perbandingan varian-varian Iban di Lembah Saribas. Ia mendeskripsikan wujudnya pelbagai alofon vokal tengah /a/ dalam bahasa Iban, misal [pYdT"] 'lihat', [sidT"] 'mereka', dan [paKkT"] 'pangkah'.

Secara morfologi bahasa Iban ini memiliki ciri-ciri yang kompleks. Berdasarkan data naratif lisan ada proses morfofonemik Iban yang dapat dirumuskan. Awalan $\{\mathrm{N}-\}$ ini memiliki 4 bentuk alomorf, yaitu $\{n\},\{m\},\{\}$, dan $\{\mathrm{N} \ll\}$. Pertama, $\{\mathrm{N}-\}+$ kata dasar berawalan huruf /t/ akan berubah menjadi /n-/, misal $\{\mathrm{N}-\}$ +/tunu w/ 'bakar' menjadi /nunuw/ 'membakar'; $\{\mathrm{N}-\}+$ /tugal/ 'tugal' menjadi / nugal/ 'menugal'. Kedua, $\{\mathrm{N}-\}+$ kata dasar berawalan huruf $/ \mathrm{b} /$ dan $/ \mathrm{p} /$ akan berubah menjadi /m-/, misal N- +/bantun/ 'cabut rumput di ladang' menjadi /mantun/'mencabut rumput di ladang'; $\{\mathrm{N}-\}+$ /pYdT"/ 'lihat' menjadi /mYdT"/ 'melihat'. Ketiga, $\{\mathrm{N}-\}+$ kata dasar berawalan huruf /a/ akan berubah menjadi /K-/, misal $\{\mathrm{N}$ - + + asu $^{\mathrm{a} h}$ / 'suruh' menjadi /Kasu'h/ 'menyuruh'; $\{\mathrm{N}-\}+$ /abas/ 'periksa' menjadi / Kabas/'memeriksa'. Keempat, $\{\mathrm{N}-\}+$ kata dasar berawalan huruf /1/ akan berubah 
menjadi /Ke-/, misal \{N - \} + /laban/ 'lawan' menjadi /KYlaban/ 'melawan'. Selain itu, proses pengimbuhan lainnya juga menarik untuk ditinjau, misal awalan $\{\mathrm{b} \ll(\mathrm{R})-\}$ dalam teks naratif lisan Iban memiliki dua alomorf, yaitu $\{b \ll-\}$ dan $\{b-\}$. Awalan ini membentuk kata kerja intransitif dari golongan kata adjektif, adverb, dan verba, misal $\{\mathrm{b} \ll(\mathrm{R})-\}+$ paKkT" 'pangkah' menjadi $b$ YpaKkT" 'berpangkah' dan $\{\mathrm{b} \ll(\mathrm{R})-\}$ + uliah 'dapat' menjadi buliah.

Teks naratif Iban ini sesungguhnya dikonstruksi oleh pencerita melalui bahasa. Bahasa yang dituturkan sang pencerita ini sangat jelas mencerminkan situasi budaya masyarakat Iban. Oleh karena itu, teks naratif lisan di atas secara gamblang menggambarkan konteks sosial dan budaya serta aspek linguistiknya, seperti semantik, fonologi, dan morfologi. Hal ini sejalan dengan yang diungkapkan Hymes (1989) bahwa selama pertuturan teks cerita berlangsung peneliti dapat memberi perhatian pada konteks sosial dan bentuk linguistik, seperti fonologi, morfologi, sintaksis, dan semantik yang muncul dalam situasi tersebut.

\section{SIMPULAN}

Hubungan antara pemakaian bahasa dan kearifan lokal dengan struktur teks naratif lisan Iban tidak dapat dinafikan. Unsur-unsur yang membangun teks lisan ternyata merupakan cerminan budaya, imajinasi, dan emosional penutur yang penuh makna simbolik. Pencerita merekonstruksi simbol-simbol kemasyarakatan ini melalui watak dan perilaku dalam plot cerita sehingga struktur yang membangun cerita lisan tetap berlandaskan pada fenomena sosial dan budaya masyarakatnya. Dengan demikian, teks naratif lisan Iban ini mewariskan banyak nilainilai kearifan lokal yang patut untuk dijadikan pendidikan tentang budaya lokal.

Hasilnya, berdasarkan analisis terhadap teks naratif lisan Iban dapat disimpulkan bahwa terdapat tiga nilai-nilai kearifan lokal. Pertama, kearifan lokal teknologi tangkap ikan tradisional yang dalam bahasa lokal disebut acar, paca", ginte", mukat, jala, tubay, dan bubu. Kedua, kearifan lokal adat berladang dan bergotong royong yang dalam bahasa Iban

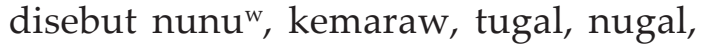
bantun, mantun, dan gutung-ruyung. Ketiga, kearifan lokal menyabung ayam dan bermain gasing yang dalam bahasa Iban disebut rabu ${ }^{\mathrm{Y}} \mathrm{K}$ dan paKkT". Teks nilai-nilai kearifan lokal ini mengandung ciri-ciri bahasa Iban secara fonologi dan morfologi serta ciri-ciri puitiknya. Selain aspek semantik, teks naratif ini juga menggambarkan bentuk-bentuk fonetik dan fonologi, seperti terdapat tujuh bunyi vokal, yaitu [i], [e], [u], [o], [Y], [a] dan [T]. Namun, secara fonemik hanya terdapat enam vokal, yaitu dua jenis vokal depan, /i/ dan /e/; dua vokal belakang, yaitu /u/ dan /o/; dan, dua vokal tengah, yaitu /Y/ dan /a/. Vokal tengah /a/memiliki alofon /T/, yang wujud pada posisi akhir kata dalam suku kata terbuka dan suku yang berakhir dengan /A/. Adanya proses diftongisasi vokal tinggi pada akhir kata terbuka. Diftongisasi seperti ini menunjukkan diftong dengan vokal geluncuran. Selain itu, vokal tinggi /u/ dan /i/ mengalami diftongisasi pada posisi suku akhir yang ditutup dengan konsonan /A/, /h/, dan /N/. Secara morfologi, berdasarkan data naratif lisan ada proses morfofonemik Iban yang dapat dirumuskan, yaitu awalan $\{\mathrm{N}-\}$ ini memiliki 4 bentuk alomorf, yaitu $\{n\},\{m\},\{N\}$, dan $\{N \ll\}$. Ada juga awalan $\{b \ll(R)-\}$ yang memiliki dua alomorf, yaitu $\{b \ll-\}$ dan $\{b-\}$.

Selanjutnya, naratif lisan atau sastra lisan berbentuk cerita merupakan satu bentuk kebudayaan yang hadir sebagai representasi peradaban lokal. Penelitian dalam bidang ini dapat diserapkan dalam linguistik, sastra, dan antropologi sebagai arus utama untuk pengembangan metodologi dan teori secara bersama-sama. Oleh karena itu, teks naratif lisan dalam 
proses pengumpulan, pengolahan, dan analisis data dapat mengintegrasikan interdisiplin ilmu. Para peneliti disarankan untuk mentranskripsi data naratif lisan menerapkan kaidah linguistik dengan melakukan transkripsi secara fonetik sehingga data dapat bermanfaat bagi ilmu linguistik. Selain itu, disarankan dalam penelitian dialektologi dan struktur bahasa data teks naratif harus menjadi sumber data primer yang penting dan utama untuk bahan analisis.

\section{UCAPAN TERIMA KASIH}

Terima kasih saya ucapkan kepada Prof. Dr. James T. Collins yang bersedia membimbing dan melibatkan saya dalam projek Iban di Lembah Sungai Saribas. Terima kasih juga kepada Prof. Emeritus Dr. Amin Sweeney Allahyarham yang pernah membimbing dan membagi ilmu riset tentang sastra lisan untuk penelitian ini. Terima kasih juga kepada The SEASREP Foundation yang telah membiayai penelitian saya.

\section{DAFTAR PUSTAKA}

Adelaar, K.A. 1995. Proto-Malayic: The Reconstruction of Its Phonology and Parts of Its Lexicon and Morphology. Pacific Linguistic C-119. Canberra: Australian National University.

Amos, Dan Ben. 1992. Folktale. Dalam Bauman Bauman, Richard (Ed.), Folklore, Cultural, Performances, and Popular Entertainments: 101-118. New York: Oxford University Press.

Atkinson, Paul \& Martyn Hammersley. 2009. "Memasuki Bidang Penelitian Kualitatif" Dalam Denzin, Norman K dan Yvonna S. Lincoln (eds), Handbook of Qualitative Research: 316-334. Diterjemahkan oleh Dariyatno dkk. Yogyakarta: Pustaka Pelajar.

Baharuddin, Shamsul Amri. 1992. Metodologi Penyelidikan Sains Sosial: Suatu Pertimbangan Kritis. Kota Kinabalu: Fakulti Sains Pembangunan, Universiti Kebangsaan Malaysia.
Bauman, Richard. 1978. Verbal Art as Performance. Rowley: Newbury House Publishers.

Bauman, Richard. 1992. Folklore. Dalam Bauman, Richard (Ed.). Folklore, Cultural,Performances, and Popular Entertainments: 29-40. New York: Oxford University Press.

Chong Shin. 2003. "Research in Saribas Valley: An Interim Report". First Workshop on Ethnic Minorities in Southeast Asia. Bangi: Institut Alam dan Tamadun Melayu, Universiti Kebangsaan Malaysia.

Collins, James T. 1983. Dialek Ulu Terengganu. Bangi: Universiti Kebangsaan Malaysia.

Dove, Michael R. 1985. “Mitos Rumah Panjang 'Komunal' dalam Pembangunan Pedesaan: Kasus Suku Kantu' di Kalimantan Barat". Dalam Dove, Michael. (Ed.). Peranan Kebudayaan Tradisional Indonesia dalam Modernisasi: 67-122. Jakarta: Yayasan Obor Indonesia.

Effendy, Chairil. 2007. "Menegaskan Kembali Identitas: Menggali Kearifan Lokal dalam Pengajaran Sastra Lisan". Makalah yang dipresentasikan dalam Kongres Bahasa Indonesia 2008, Jakarta 28 Oktober - 1 Nopember 2008.

Freeman, Derek. 1992. The Iban of Borneo. Kuala Lumpur: S. Abdul Majeed \& Co.

Geertz, Clifford. 1983. Local Knowledge. New York: Basic Books, Inc.

Geertz, Clifford. 1992. Tafsir Kebudayaan. Diterjemahkan oleh Francisco Budi Hardiman. Yogyakarta: Kanisius.

Hutomo, Suripan Sadi. 1991. Mutiara yang Terlupakan: Pengantar Studi Sastra Lisan. Surabaya: HISKI.

Hymes, Dell. 1981. In Vain I Tried to Tell You: Essays in Native American Ethnopoetics. Philadelphia: University of Pennsylvania Press.

Hymes, Dell. 1989. Foundations in Sociolinguistics: An Ethnograpic Approach. 
Philadelphia: University of Pennsylvania Press.

Jakobson, Roman. 1996. “Linguistik dan Bahasa Puitik". Dalam Panuti Sudjiman dan Art van Zoest (Ed.). SerbaSerbi Semiotika: 64-79. Jakarta: Gramedia.

Jensen, Erik. 1974. The Iban and Their Religion. Oxford: The Clarendon Press.

Kadarisman, A. Effendi. 1999. 'Wedding Narratives as Verbal Art Performance: Explorations in Javanese Poetics". Dissertation. University of Hawai'i.

Kadarisman, A. Effendi. 2010. Mengurai Bahasa Menyibak Budaya: Bunga Rampai Linguistik, Puitika, dan Pengajaran Bahasa. Malang: UIN-Maliki Press.

King, Victor T. 1993. The Peoples of Borneo. Oxford: Blackwell Publishers.

Padoch, Christine. 1982. Migration and its Alternatives Among the Iban of Sarawak. The Hague: Martinus Nijhoff.

Peursen, C.A. van. 2001. Strategi Kebudayaan. Kanisius: Yogyakarta.

Putra, Heddy Shri Ahimsa, 2008. “Ilmuan Budaya dan Revitalisasi Kearifan Lokal: Tantangan Teoretis dan Metodologis." Pidato dalam Rapat Senat Terbuka Dies Natalis ke-62 Fakultas Ilmu Budaya, Universitas Gadjah Mada, Yogyakarta.

Richards, Anthony. 1981. An Iban-English Dictionary. Petaling Jaya: Fajar Bakti.
Sandin, Benedict. 1977. Gawai Burong. Pulau Pinang: Universiti Sains Malaysia

Sherzer, Joel and Anthony C Woodbury. 1987. Native American Discourse: Poetics and Retoric. New York: Cambridge University Press.

Sherzer, Joel. 1983. Kuna Ways of Speaking: an Ethnographic Perspective. Texas: University of Texas Press.

Sweeney, Amin. 1974. "Professional Malay Story-Telling: Some Questions Of Style And Presentation"., pp 47-99. Ann Arbor: Center for South and Southeast Asian Studies, The University of Michigan.

Sweeney, Amin. 1976. "The Pak Pandir Cycle of Tales". Journal of the Malaysian Branch Royal Asiatic Society, 49(1): 15-88.

Taslim, Noriah dan Chemaline Osup. 2013. Ensera Ayor: Epik Rakyat Iban. Penang: Penerbit Universiti Sains Malaysia.

Tedlock, Dennis. 1992. Ethnopoetics. Dalam Bauman, Richard (Ed.). Folklore, Cultural, Performances, and Popular Entertainments: 81-85. New York: Oxford University Press.

Teeuw, A. 1984. Sastra dan Ilmu Sastra: Pengantar Teori Sastra. Jakarta: Pustaka Jaya. 